University of Wollongong

Research Online

Faculty of Engineering and Information

Faculty of Engineering and Information

Sciences - Papers: Part A

Sciences

$1-1-2016$

\title{
Renewable energy management in a remote area using Modified Gravitational Search Algorithm
}

Sahand Ghavidel

Shiraz University of Technology

Jamshid Aghaei

Shiraz University of Technology, jamshid@uow.edu.au

Kashem M. Muttaqi

University of Wollongong, kashem@uow.edu.au

Alireza Heidari

University of New South Wales

Follow this and additional works at: https://ro.uow.edu.au/eispapers

Part of the Engineering Commons, and the Science and Technology Studies Commons

Research Online is the open access institutional repository for the University of Wollongong. For further information contact the UOW Library: research-pubs@uow.edu.au 


\title{
Renewable energy management in a remote area using Modified Gravitational Search Algorithm
}

\begin{abstract}
In this paper, a small remote area which is located in Nigeria has been considered as a model to be tested by a managing scheme for providing both electricity and water. In this strategy, the groundwater is pumped into a water tank which can be later used for supplying required irrigation and drinking water. A PAT (Pump as Turbine) is used as a hybrid system for supplying electricity and water as well as storing water in the water tank. Also, a PV (photovoltaic plant), a package of batteries (BAT) in addition to a diesel ICE (internal combustion engine) are used and optimized along with the best size of devices and managing system, with the purpose of obtaining the maximum economical operating strategy. In this paper, two cases are considered to assess the effectiveness of the system under study. Firstly, all of the mentioned devices are used to show how internal combustion engine system dominates all the other components due to the low cost of fuel. In the second case, all renewable resources have been exploited and optimized in order to make a $100 \%$ renewable system with least possible cost. Having about 53 variables makes this problem very complicated which requires to be solved by an algorithm with more accuracy. Therefore, a MGSA (Modified Gravitational Search Algorithm) with an adapted mutation tactic is used to find the best cost and management strategy. In the first case, although the cost of diesel oil is very low, by using the PAT, about $5 \%$ of diesel oil consumption is reduced. In the second case, in order to make a $100 \%$ renewable system, the size of PV is enlarged approximately 16 times in comparison with the first case. The hybrid PV-PAT storing structure is capable to deliver the water for irrigation and domestic requirements as well as $9 \%$ of the electricity needed for the rural community.
\end{abstract}

\section{Keywords}

search, algorithm, management, remote, renewable, area, energy, modified, gravitational

\section{Disciplines}

Engineering | Science and Technology Studies

\section{Publication Details}

S. Ghavidel, J. Aghaei, K. M. Muttaqi \& A. Heidari, "Renewable energy management in a remote area using Modified Gravitational Search Algorithm," Energy, vol. 97, pp. 391-399, 2016. 


\section{Renewable Energy Management in a Remote Area using Modified Gravitational Search Algorithm}

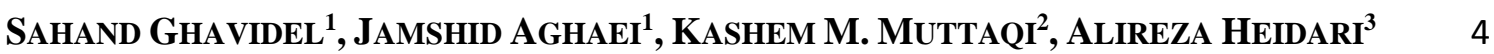

${ }^{1}$ Department of Electronics and Electrical Engineering, Shiraz University of 6

Technology, Shiraz, Iran $\quad 7$

${ }^{2}$ Australian Power Quality and Reliability Centre, SECTE, University of Wollongong, 8

Wollongong, Wollongong, NSW, Australia 9

${ }^{3}$ School of Electrical Engineering and Telecommunications, the University of New 10

South Wales, NSW, Sydney, Australia 11

Abstract- In this paper, a small remote area which is located in Nigeria has been

considered as a model to be tested by a managing scheme for providing both electricity

and water. In this strategy, the groundwater is pumped into a water tank which can be

later used for supplying required irrigation and drinking water. A Pump as Turbine

(PAT) is used as a hybrid system for supplying electricity and water as well as storing

maximum economical operating strategy. In this paper, two cases are considered to

assess the effectiveness of the system under study. Firstly, all of the mentioned devices

are used to show how internal combustion engine system dominates all the other

components due to the low cost of fuel. In the second case, all renewable resources 
which requires to be solved by an algorithm with more accuracy. Therefore, a Modified

Gravitational Search Algorithm (MGSA) with an adapted mutation tactic is used to find

the best cost and management strategy. In the first case, although the cost of diesel oil is

very low, by using the PAT, about $5 \%$ of diesel oil consumption is reduced. In the

second case, in order to make a $100 \%$ renewable system, the size of PV is enlarged

approximately 16 times in comparison with the first case. The hybrid PV-PAT storing

structure is capable to deliver the water for irrigation and domestic requirements as well

as $9 \%$ of the electricity needed for the rural community.

Keywords: Gravitational Search Algorithm, Modified techniches, Photovoltaic

\begin{tabular}{|c|c|c|c|}
\hline$F_{b e s t}(t)$ & $\begin{array}{l}\text { best fitness from all achieved results } \\
\text { for each agent }\end{array}$ & $\varepsilon$ & constant value \\
\hline$F_{\text {worst }}(t)$ & $\begin{array}{l}\text { worst fitness from the results for } \\
\text { each agent }\end{array}$ & $a_{i}(t)$ & the accelartion for each agent \\
\hline$n$ & number of variables & $v_{i}^{(t)}$ & $\begin{array}{l}\text { velocity of each agent for each } \\
\text { iteration }\end{array}$ \\
\hline$M_{i}(t)$ & mass designed for each agent & $x_{i}^{(t)}$ & $\begin{array}{l}\text { position of each agent for each } \\
\text { iteration }\end{array}$ \\
\hline$f_{i}(t)$ & the fitness function for each agent & $R_{i j}(t)$ & $\begin{array}{l}\text { Euclidean space among agent } \\
\mathrm{i} \text { and agent } \mathrm{j}\end{array}$ \\
\hline $\operatorname{rand}_{j}()$ & random number & $G$ & Gravitational constant \\
\hline$X_{j i}^{k}$ & $\begin{array}{l}i^{t h} \text { member of each agent in the } \\
\text { iteration } k \text { for the current } \\
\text { existingagent } j\end{array}$ & $M^{k}$ & mean value of the population \\
\hline$X_{j, \text { trial }}^{k}$ & $\begin{array}{l}i^{t h} \text { member of each agent in the } \\
\text { iteration } k \text { for the trial agent } j\end{array}$ & $A_{\text {res }}$ & capacity of reservoir \\
\hline
\end{tabular}




\begin{tabular}{|c|c|c|c|}
\hline$\theta$ & learning degree & $A_{P A T}$ & capacity of BAT \\
\hline$K_{\max }$ & the determined number of iterations & $c_{\text {Fuel }}$ & price of fuel in $€$ per Liter \\
\hline$w w$ & weight factor & $m_{h}$ & fuel mass flow rate \\
\hline NPOP & the maximum number of agents & $\Delta t$ & time interval \\
\hline$c_{P V}$ & price of $\mathrm{PV}$ in $€$ per $\mathrm{m}^{2}$ & $P_{\text {users }}$ & load demand \\
\hline$c_{I C E}$ & price of ICE in $€$ per $\mathrm{kW}$ & $P_{P V}$ & generated power \\
\hline$c_{B A T}$ & price of BAT in $€$ per $\mathrm{kWh}$ & $P_{I C E}$ & power of ICE \\
\hline$c_{\text {res }}$ & price of reservoir in $€$ per $\mathrm{m}^{3}$ & $P_{B A T}$ & power of BAT \\
\hline$c_{P A T}$ & price of PAT in $€$ per $\mathrm{kW}$ & $P_{P A T}$ & power of PAT \\
\hline$S_{P V}$ & capacity of PV & $V$ & tank volume \\
\hline$S_{I C E}$ & capacity of ICE & $Q_{\text {tank }}$ & $\begin{array}{l}\text { amount of flow rate of the } \\
\text { reservoir }\end{array}$ \\
\hline$S_{B A T}$ & capacity of BAT & $Q_{\text {users }}$ & $\begin{array}{l}\text { water suitable for drinking } \\
\text { required for rural community }\end{array}$ \\
\hline$F\left(X_{j}\right)$ & $\begin{array}{l}\text { main objective function and the } \\
\text { constraints }\end{array}$ & $Q_{i r r}$ & $\begin{array}{l}\text { amount of water required for } \\
\text { irrigation }\end{array}$ \\
\hline$f\left(X_{j}\right)$ & main objective function & $Q_{P A T}$ & $\begin{array}{l}\text { amount of flow rate related to } \\
\text { the PAT system }\end{array}$ \\
\hline$\lambda_{z}$ & $\begin{array}{l}\text { penalty factor of the constraint } \\
\text { violation } z\end{array}$ & $V I O L_{z}$ & $\begin{array}{l}\text { value of the constraint } \\
\text { violation } z \text { repository }\end{array}$ \\
\hline
\end{tabular}


These days, the act of making remote areas profitable of renewable sources is a 2 possibility due to a favorable combination of circumstances which can gives many 3 people having opportunity to gain access to electricity and water. For the areas that the 4 electricity network are not obtainable for usage, the stand-alone photovoltaic pumping 5 systems can be used for supplying electricity in addition to required irrigation and 6 drinkable water. Also, the environmental issues, energy saving and using lower amount 7 of fossil resources with higher efficiency has to be considered more than ever. In 8 addition, there are some difficulties in remote areas such as right of way and 9 transmission line expansion. However, the usage of local resources in particular the 10 renewable ones, can give the people living in remote areas, an opportunity to gain access 11 to electricity with more reliability.

The reliable access to both irrigation and drinking water is also very important to people living in these remote areas. Recent years, many strategies have been suggested about coordinating pumping systems with local renewable sources such as Ref. [1] which investigated the coordination of supplying required water with local renewable energy resources in the inner area of Nigeria. Ghoneim in [2] found diesel engines very 17 cheap, if well designed, while Ref. [3] discovered them not suitable in Algeria from economical point of view. Khelif et al. in [4] proposes a PV-diesel engine system by analyzing the fuel cost, while Ref. [5] analyzes the greenhouse effect of the similar system. Ngan and Tan in [6] also added a set of wind turbines to a similar arrangement of elements. 
Using hydrogen storage has been carefully practiced and designed in Ref. [7]. 1 González et al. in [8], having the requisite qualities for normal growth and development 2 of hydrogen production in accompaniment with wind power have been analyzed. 3 Beccali et al in [9] have computed different sites of hydrogen production in the matter of 4 their costs and dependence on wind energy. Ref. [9] tries to optimize a large-wind- 5 hydrogen strategy with regards to the sizes of these devices, and a wind-PV strategy is 6 introduced and optimized in Ref. [10].

Another important storage system is Compressed Air Energy Storage (CAES) which 8 makes available a lot of added supports [11] and it can be used either as a sustenance 9 [12] or in a combined heat and power system [13]. Safaei and Keith in [14] analyzed 10 different benefits of this solution including economic and environmental issues. Kim and Lee in [15] studied CAES as a storage part in a new hybrid system integrating with 12 pumped hydro plants which are a new joined together technology. These new technologies are frequently used as a sustenance for wind energy systems [16].

According to the good performance and life cycle of small solar supported heat driven chillers, the use of these technologies have been extended to such structures with intended to deliver a widespread study of these solar supported cooling systems (using solar thermal or PV). Beccali et al. in [18] provided a more widespread study over an assessment of these solar supported cooling systems. In the paper, two more arrangements of these systems were studied to additionally define the PV supported systems. Also, a performance comparison between the Italian and the Brazilian context 
The water tank is also a storage system which has been used as a new storage strategy

for pumped hydro power plants and can function as a supporter energy source along

solar power plants [20]. Refs. [21, 22] evaluated the use of PAT in hydro power plants in 3 the matters of the system's performance and choosing right pump for the system.

It is very demanding to make an arrangement scheme for hybrid systems due to their 5 complex system [23]. Therefore, for solving these complex systems, a variety of 6 techniques have been presented. Chicco and Mancarella in [24] proposed a model based 7 on matrix optimization for tri-generation systems, and also Chicco and Mancarella in 8 [25] reported a comprehensive review of a variety of techniques for the optimization of 9 such systems.

Further explanations on Nigeria remote area background are provided as follows. In

[1], Cloutier and Rowley are completed an economical investigation in the central areas

of Nigeria with the purpose of evaluating the practicality of renewable energy resources

to alternate the conventional pumping systems. Hamidat et al. in [26] subjects to an analysis with the intention of increment of the efficiency of a PV-PAT system connected to electricity local grid for different kinds of cultivated plant that is grown commercially on a large scale in Nigeria. Kaldellis et al. in [27] declares a plan for a stand-alone 17 photovoltaic pumping system equipped with batteries for storage purposes, capable of covering irrigation and required water suitable for drinking in remote areas. Ohunakin et al. in [28] are studied and argued the present viewpoints of solar energy exploitation by means of a renewable energy choice in Nigeria as a position of supportable progress.

Gravitational Search Algorithm (GSA) is a new artificial intelligent algorithm presented in 2009 [29], and is used in different objective functions with obtaining better results than those obtained by many other algorithms such as particle swarm 
optimization (PSO) and genetic algorithm (GA). Even though this algorithm is derived

from a simple concept, but, it has a great power in solving optimization problems. It has

also a little drawback regarding to trapping in local optimal positions. There are a lot of

3

modifications have been accomplished on this algorithm. In order to improve the typical

4

GSA, Han and et al. in [30] recommend a robust hybrid GSA which makes better the 5

global search as well as exploiting the sequential quadratic programming to speed up the 6

local search. Provas and Chandan in [31] outlines an effective quasi-oppositional GSA 7

to resolve short term hydrothermal arrangement problem. Also, for solving the same 8

problem as [31] in power system, Gouthamkumar et al. in [32] proposed a disruption 9

based gravitational search algorithm which utilized a successful approach to handle 10

system constraints.

In order to tackle the mentioned drawbacks, a new self-adaptive learning strategy is

used which includes two updating approaches to increase the operation of the GSA

algorithm. The first strategy is related to transferring data between the agents. The latter

strategy is used for helping the algorithm to flee from local optima. By using a

probability technique, each agent chooses one of these two approaches with better

effectiveness to acquire an enhanced condition. In this paper, proposed Modified

gravitational search algorithm (MGSA) applied to a hybrid system including PAT, PV,

BAT and ICE aimed at providing electrical energy and supplying irrigation and drinkable water to a remote area in Nigeria.

This paper is arranged as follows. Section 2 describes a brief overview of GSA and 
The GSA as a novel artificial intelligent algorithm is based on the rule that was 3 derived from the law of gravity. This algorithm is worked by the principles of mass 4 reciprocal action using the theory of Newtonian laws. In physics, gravitation is an 5 inclination of objects with themselves [29, 33, 34]. A system is supposed with $\mathrm{n}$ masses 6 to depict the presented method which can be seen as follows,

$$
x_{i}=\left[x_{i}^{1}, x_{i}^{2}, \ldots, x_{i}^{n}\right]
$$

After calculating the objective functions for all agents, the best fitness from all 8 achieved results is called $F_{b e s t}(t)$ and the worst fitness from the results is 9 called $F_{\text {worst }}(t)$. After calculating the best and worst fitness, the mass designed for each agent can be easily calculated by,

$$
M_{i}(t)=\frac{Q_{i}(t)}{\sum_{i=1}^{n} Q_{i}(t)},
$$

where $Q_{i}(t)$ can be calculated for each existing agent by following function,

$$
Q_{i}(t)=\frac{f_{i}(t)-F_{\text {worst }}(t)}{F_{\text {best }}(t)-F_{\text {worst }}(t)}
$$

Next, the accelartion for each agent must be calculated. For doing so, the total force applied on each of them is calculated by means of using Newton rules as follows, 


$$
F_{i}(t)=\sum_{j \in \text { Kbest }} \operatorname{rand}_{j \neq i}() G(t) \frac{M_{j}(t) M_{i}(t)}{R_{i j}(t)-\varepsilon}\left(x_{j}(t)-x_{i}(t)\right)
$$

where $\operatorname{rand}_{j}()$ is a number which is randomly and uniformly distributed among 0 and 1 for each agent. Also, $\varepsilon$ is a constant value which is very slight and small. By using the 2 calculated total force, the accelartion for each agent can be calculated as follows using 3 Newton rules,

$$
\begin{aligned}
a_{i}(t) & =\frac{F_{i}(t)}{M_{i}(t)} \\
& =\sum_{j \in \text { Kbest }} \operatorname{rand}_{j \neq i}() G(t) \frac{M_{j}(t) M_{i}(t)}{R_{i j}(t)-\varepsilon}\left(x_{j}(t)-x_{i}(t)\right)
\end{aligned}
$$

The following formulas show the modified velocity and position of each agent 5 calculated using the the accelartion:

$$
\begin{gathered}
v_{i}^{(t+1)}=\operatorname{rand}_{2}() \times v_{i}^{(t)}+a_{i}(t), \\
x_{i}^{(t+1)}=x_{i}^{(t)}+v_{i}^{(t+1)},
\end{gathered}
$$

where $\operatorname{rand}_{1}()$ and $\operatorname{rand}_{2}()$ are numbers which are randomly and uniformly distributed 7 among 0 and 1 for each agent. $R_{i j}(t)$ is the Euclidean space among agent $i$ and agent $j$. $K_{\text {best }}$ is the finest value of $K$ agents which their value reduced by increasing the value of 9 iteration. As well as $K$, the value of Gravitational constant $(\mathrm{G})$ is decreased by each 10 iteration which can be seen as follows,

$$
G^{k}=G_{0} \times \exp \left(\varpi \times \frac{\text { Iter }}{\text { Iter }_{\max }}\right)
$$

where $G_{0}$ and $\varpi$ are set to 100 and 20, respectively [34]. 
Comparing with PSO algorithm, GSA algorithm has two privileges [29, 34]. Firstly, 1 the act of moving in PSO is calculated only by $P_{\text {best }}$ and $G_{\text {best }}$, but the act of moving in 2 GSA is designed through all forces of other agents. Secondly, contrary to PSO 3 algorithm, the prevailing remoteness among answers affects the new situation of each 4 agent in GSA.

\section{2. Self-adaptive learning strategy (SALS) used for GSA}

In order to increase the capibility of the GSA, a novel self-adaptive learning strategy

which is shortly called SALS is used and implemented to the original algorithm . To do 8 so, two methods have been utilized, which each of them is related to different iterations 9 by implementing in a probabilistic way. Each method utilizes a value that is probilistic 10 and based on the capability of the related apprising technique. In addition, in order to help each agent determine one method among the two methods which can be seen as follows, a tool which is called the Roulette Wheel Mechanism (RWM) is used.

Method 1: In the first technique, the enhanced algorithm exploited an exterior memory for obtaing the finest solution called $G_{\text {best }}$ which obtained from solutions saved until now. EGSA can use this $G_{\text {best }}$ for updating the solutions as follows,

$$
\begin{gathered}
x_{j, \text { method } 1}^{k}=x_{j}^{k}+\operatorname{rand}\left(G_{\text {best }}^{k}-L F^{k} M^{k}\right) \\
j=1, \ldots, N_{1}
\end{gathered}
$$

where rand is the random value between 0 and $1 . M^{k}$ is the mean value of the population. $N_{l}$ is the amount of agents which the technique 1 are using, and the value of $L F$ can be either 1 or 2 [34].

Method 2: This second method is used to diverse the solutions, avoid lack of 20 movement and being trapped in local optima. Five agents can be choosed randomly for 
each agent $j$ in the way that $m_{1} \neq m_{2} \neq m_{3} \neq m_{4} \neq m_{5} \neq j$. By using these agents, a trial

$$
\begin{aligned}
X_{j, \text { trial }}^{k} & =X_{m 1}^{k}+\operatorname{rand} 1\left(X_{m 2}^{k}-X_{m 3}^{k}\right) \\
& +\operatorname{rand} 2\left(X_{m 4}^{k}-X_{m 5}^{k}\right), \quad j=1, \ldots, N_{1}
\end{aligned}
$$

where rand 1 and rand 2 are numbers which are randomly and uniformly distributed 3 among 0 and 1 for each agent. Also, $N_{1}$ is the number of agents which the technique 24 are using. EGSA can use this method for updating the solutions as follows [34],

$$
X_{j, \text { method2 }}^{k}= \begin{cases}X_{j, \text { trial }}^{k} & \text { if }(\text { rand } \leq 0.5) \\ X_{j i}^{k} & \text { else }\end{cases}
$$

where $X_{j i}^{k}$ and $X_{j, \text { trial }}^{k}$ are the $i^{\text {th }}$ member of each agent in the iteration $k$ for the current 6 existing and trial agent $j$, correspondingly. The better value is selected as a solution 7 between $X_{j, \text { method2 }}^{k}$ and $X_{j}^{k}[34]$.

The probability of both mentioned approaches are calculated by [35],

$$
\operatorname{prob}_{\text {method1 }, 2}=(1-\theta) \operatorname{prob}_{\text {method } 1,2}+\theta \frac{a_{\text {method } 1,2}}{k_{\text {max }}}
$$

where $\theta$ is a learning degree in the direction of adjusting the learning quickness of the 10 algorithm which is selected to be 0.142 [34]. $K_{\max }$ is the determined number of iterations, and $a_{\text {method } 1,2}$ is the accumulator which is updated individually for each strategy as follows $[34,35]$,

$$
a_{\text {method } 1,2}=a_{\text {method } 1,2}+w w_{1,2}
$$


where $w w$ is a weight factor which is assigned for each agents in order to help them

$$
\begin{gathered}
w w_{j}=\frac{\log (N P O P-j+1)}{\log (1)+\ldots+\log (N P O P)}, \\
j=1, \ldots, N P O P
\end{gathered}
$$

where $N P O P$ is the maximum number of agents. In a final manner, the normalised 3 probability values can be defined as follows,

$$
\operatorname{Prob}_{\text {method1,2 }}=\frac{\text { Prob }_{\text {method1,2 }}}{\left(\operatorname{prob}_{1}+\text { prob }_{2}\right)}
$$

In the EGSA solution technique, one trial solution method is chosen according to the 5 probability using RWM. Then, the chose method is subsequently used for related target 6 solution. Fig. 1 shows the flowchart of the EGSA algorithm. 


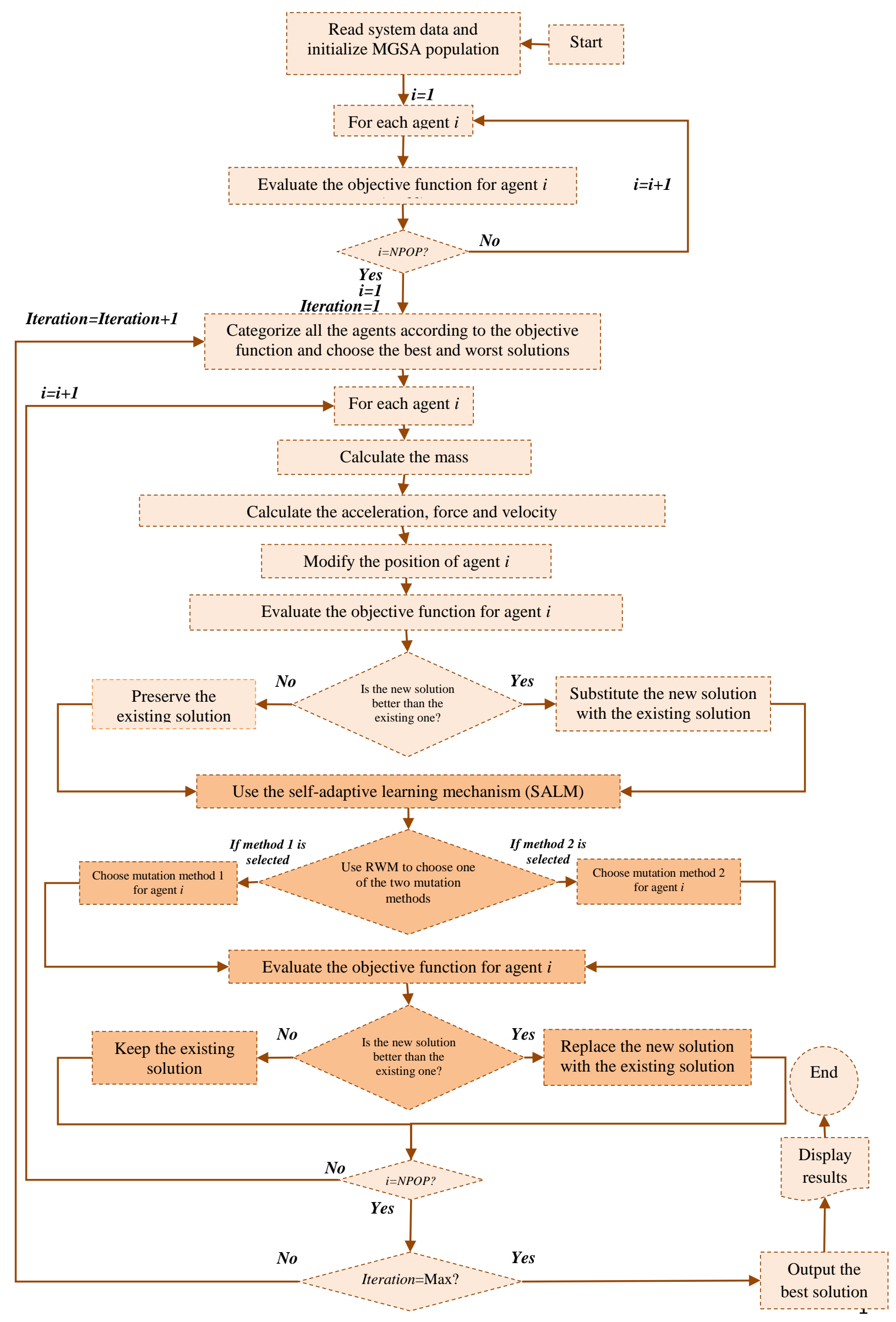


Fig. 2 displays a symbolic form of the system under study which has been optimized

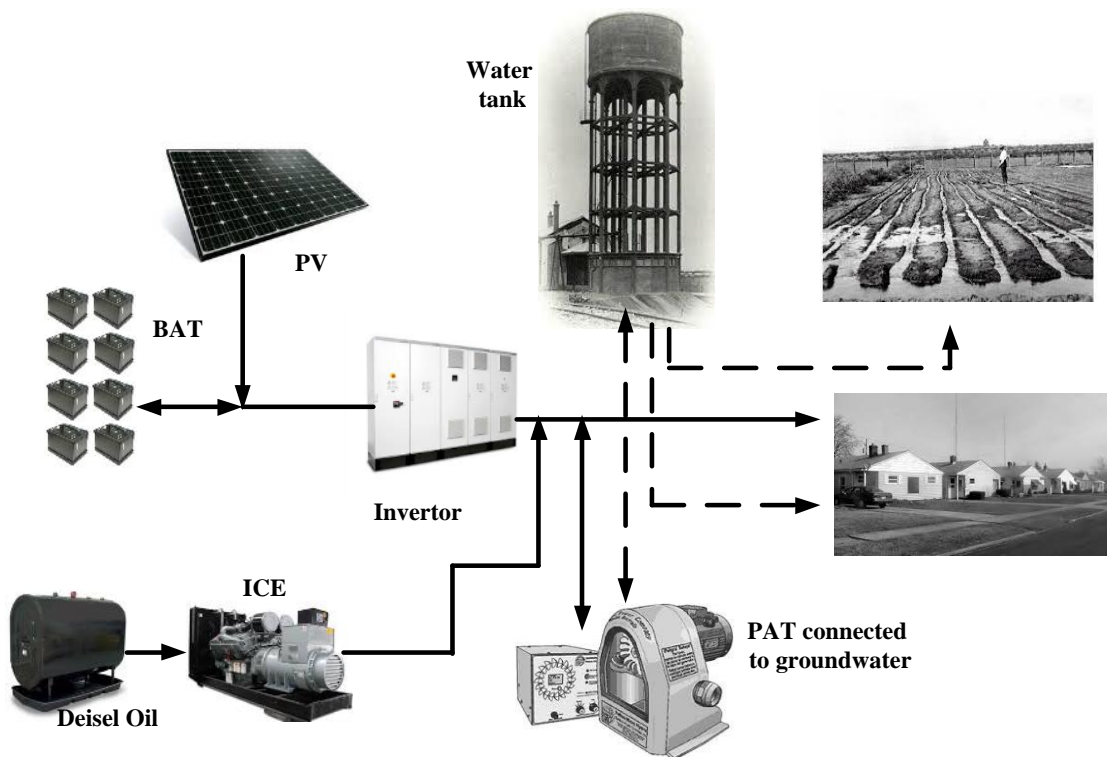

Figure 2. Diagram of the structure under study: solid lines indicate the electrical conduction and dot lines show water transmission. 
The amount of electricity and water suitable for drinking which are used in the village for a given day in summer can be seen in Fig. 3 and Fig. 4 [23]. Notice that most of the 2 electricity in the village is consumed by people in the duration of time when PV cannot 3 produce energy. The daily supplying dry land with water for irrigation is $17 \mathrm{~m}^{3}$ [26].

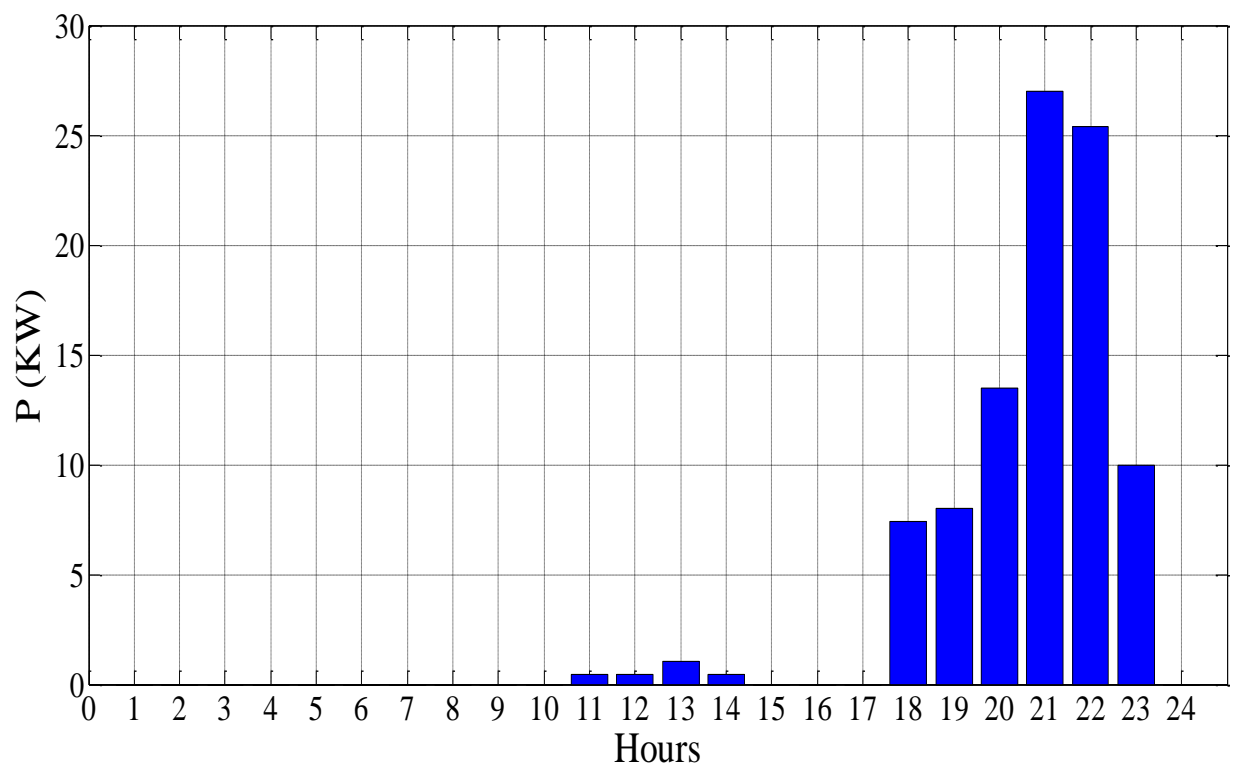

Figure 3. Hourly electricity demand.

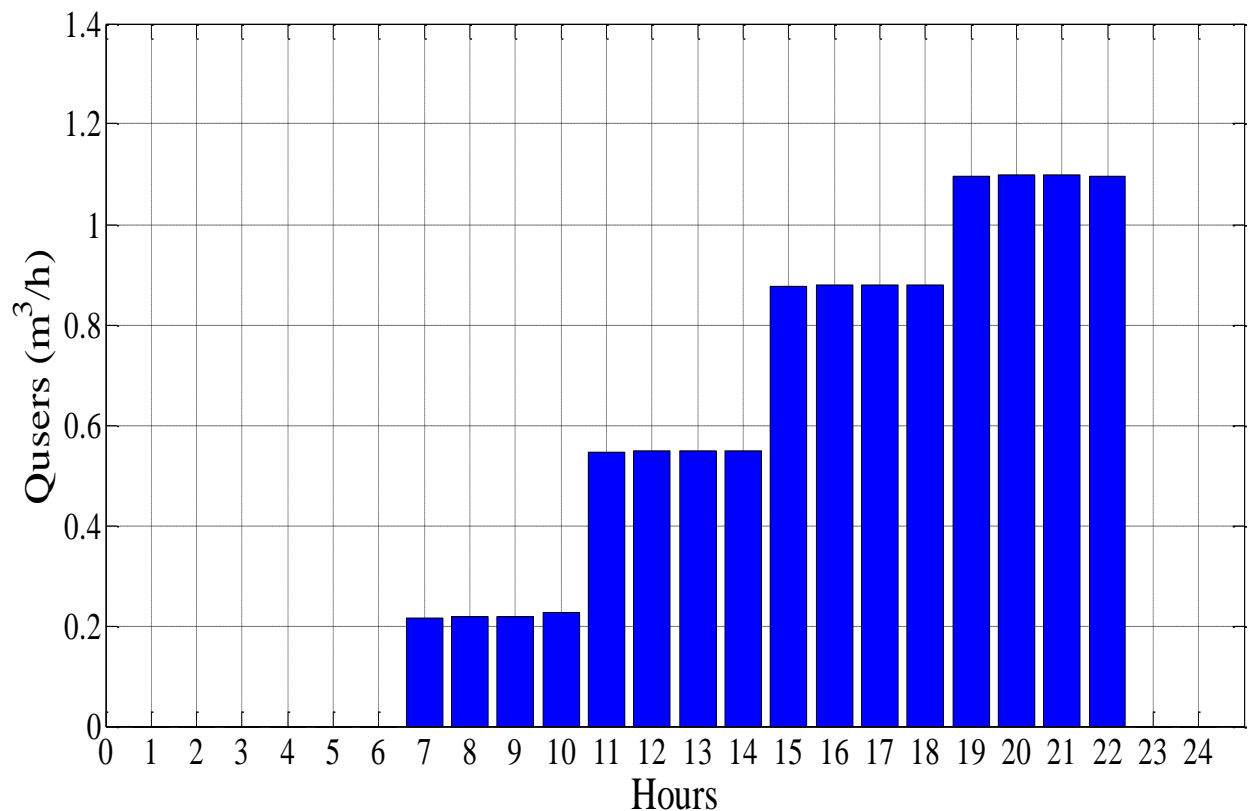

Figure 4. Hourly water demand. 
Water is moved up from underground water $60 \mathrm{~m}$ deep, and the concrete tank provides the water storage in the pumping system. The head loss is considered in the 2 flow rate as well as the considered pipes length [23].

The energy of pumping for water suitable for drinking and irrigation system and also 4 the required electricity are provided with the PV and diesel engine system. The pumping 5 system can be used as a pump to store water in the reservoir which can be used later in 6 the turbine to supply power for users which helps to increase the efficiency of the whole 7 system $[23,36]$. The lower quantity of the volumetric flow rate is $30 \%$ and the upper 8 amount of it is $100 \%$ of the full flow rate through pumping condition. The lower rate of 9 the volumetric flow rate is $50 \%$ and the upper amount of it is $100 \%$ of the maximum flow rate during turbine operation mode. Also, the amount of the reservoir tank in the last hour of each day is compelled to be the same as the amount of the beginning of the day [23].

In order to increase the storage capacity and further improvement in the efficiently of the system, a BAT is provided. The lowest amount of SOC for the pack of batteries is considered to stay at $10 \%$ and the maximum quantity of allowable DOD is considered to be $90 \%$. It is considered that a maximum determined value of discharge rate remains at $0.2 \mathrm{~kW} / \mathrm{kWh}$ of maximum amount of BAT's SOC which makes the efficiency of the battery about $75 \%$. Also, similar to the level of the reservoir, the SOC of the battery in the last hour of each day is compelled to be the same as the amount of the beginning of the day. The efficiency of the ICE system is 0.328 by having the smallest possible quantity of $30 \%$ of the load. The complete duration life of the different component of the 
reservoir have the life span about 10, 20, and 15 years, respectively, whereas the life span of battery is calculated by the optimization problem [23].

The information associated with hourly solar irradiance, hourly air temperature as 3 well as hourly wind velocity have been derived from Refs [28, 37-40] which have been 4 utilized to predict in advance the hourly electrical energy provided using the 5 photovoltaic plant. The particular photovoltaic hourly provided electrical energy is 6 shortened in Fig. 5 which considers the dependency of the alteration effectiveness of the 7 PV unit temperature [41] making an allowance for a tilt angle of 15 degree. The prices of every components and the fuel can be seen in Table 1 .

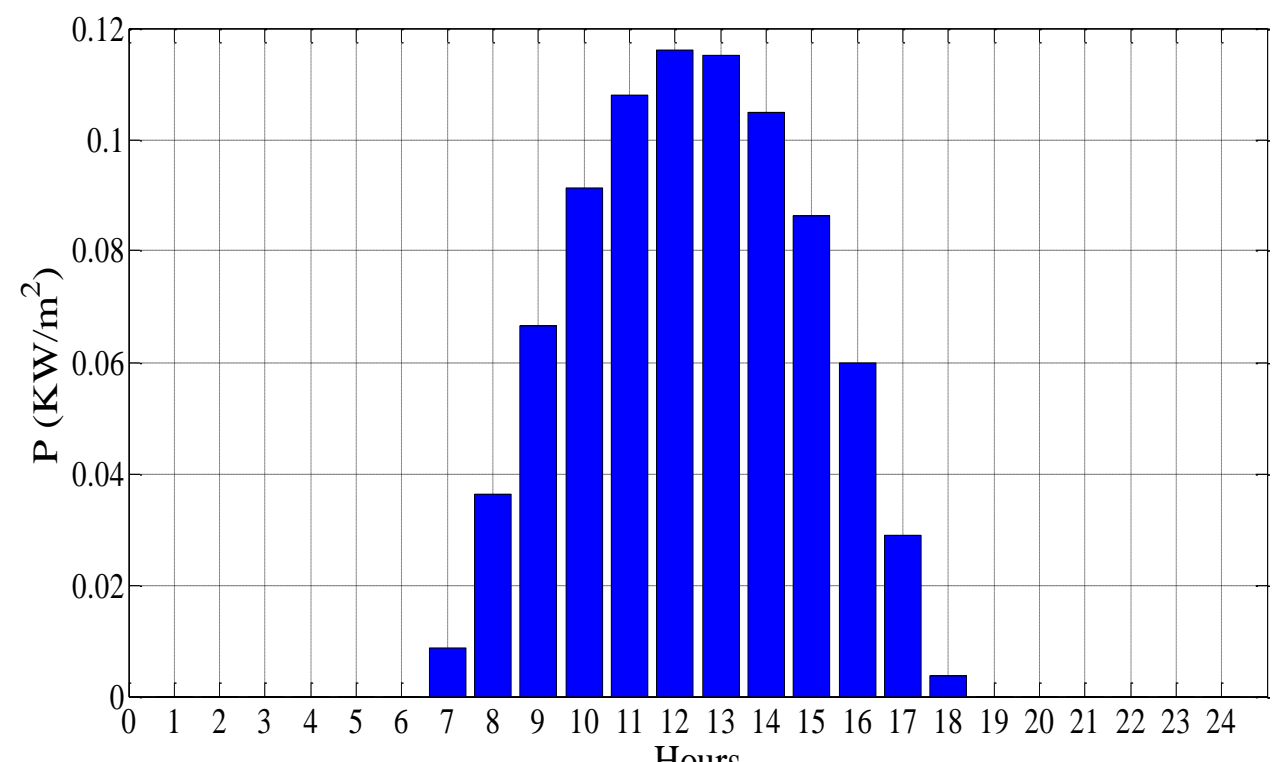

Hours

Figure 5. Hourly electrical energy provided using the photovoltaic plant. 


\begin{tabular}{cc}
\hline Parameters & Values \\
\hline PV & $340 € / \mathrm{m} 2$ \\
ICE & $1000 € / \mathrm{kW}$ \\
BAT & $210 € / \mathrm{kWh}$ \\
Reservoir & $100 € / \mathrm{m} 3$ \\
PAT & $180 € / \mathrm{kW}$ \\
Fuel & $0.66 € / \mathrm{Liter}$ \\
\hline
\end{tabular}

The intention of this optimization procedure is to optimize the size values of the PV, 4 ICE, PAT, and BAT as well as water tank and their operation strategy. This objective 5 function can be expressed as [23],

$$
\begin{aligned}
f\left(X_{j}\right) & =\left(c_{P V} S_{P V}+c_{I C E} S_{I C E}+c_{B A T} S_{B A T}\right. \\
& \left.+c_{r e s} A_{r e s}+c_{P A T} A_{P A T}\right)+\sum_{h=1}^{24} c_{\text {Fuel }} m_{h} \Delta t
\end{aligned}
$$

where $m_{h}[\mathrm{~kg} / \mathrm{h}]$ is the fuel mass flow rate, and $\Delta t$ is the time interval with the given 7 amount of 1 hour. As mentioned before, $c_{B A T}$ is evaluated by considering batteries life 8 span. Notice that $S_{I C E}$ is imposed to be 0 , when the system is using only renewable 9 energy. Number of variables are 53 which include 48 hourly decision variables, fuel and 10 water mass flow rate in the pump as turbine system, and 5 devices size. The power balance constraint can be written as follow [23],

$$
P_{\text {users }}=P_{P V}+P_{I C E}+P_{B A T}+P_{P A T}
$$


where $P_{\text {users }}$ is the load demand, $P_{P V}$ is the PV generated power, $P_{I C E}$ is the power of the

ICE. $P_{P A T}$ and $P_{B A T}$ are the power of the PAT and BAT systems, respectively which can 2 be either positive or negative.

Other important constraints are related to the value of reservoir volume and the flow rates balance which can be defined as follow [23],

$$
\begin{gathered}
0 \leq V \leq V_{\text {max }} \\
Q_{\text {tank }}=Q_{\text {users }}+Q_{\text {irr }}+Q_{P A T}
\end{gathered}
$$

where $V$ is the tank volume (m3), $Q_{\text {tank }}$ is the amount of flow rate of the reservoir which 6 can be either positive or negative values, $Q_{\text {users }}$ is the water suitable for drinking required 7 for rural community, $Q_{i r r}$ is the amount of water required for irrigation. Also, $Q_{P A T}$ is the 8 amount of flow rate related to the PAT system.

It is assumed that the amount of water in the reservoir and battery charge in the last hour 10 of each day is compelled to be the same as the amount of the beginning of the day which can be expressed as [23],

$$
\begin{gathered}
V_{h=24}=V_{0} \\
\operatorname{SOC}_{h=24}=\mathrm{SOC}_{0}
\end{gathered}
$$

Finally, the overall objective cost function and the constraints of the system can be written as the sum of the two terms including the main objective function and the constraints as follow,

$$
F\left(X_{j}\right)=\min f\left(X_{j}\right)+\sum_{z=1}^{n c} \lambda_{z}\left[V I O L_{z}\right]^{2}
$$


where $n c$ is the total quantity of system constraints, VIOL $L_{z}$ is value of the constraint

violation $z$ and $\lambda_{z}$ is the penalty factor which can be selected independently for each 2 constraint.

\section{Results and discussions}

\section{Case 1: exploiting renewable energy sources along ICE}

Table 2 shows the best cost result calculated by MGSA algorithm which is compared 6 to the results obtained by other techniques. Judging from Table 4, it can be seen that the 7 minimum cost is $11939.92 €$, with an average cost of $11939.93 €$, and a maximum cost of $11939.93 €$ which are less in comparison with the other used algorithms. As it can be 9 seen from the results, the minimum, maximum and the average cost values are very 10 close to each other which clearly show the superiority and robustness of the proposed

algorithm. Also the convergence of the algorithms for the problem with minimum cost 12 is shown in Fig. 6. The calculated optimum devices sizes are $P V=10.39 \mathrm{~m}^{2}, \mathrm{ICE}=27 \mathrm{~kW}$, 13 $\mathrm{PAT}=3.1 \mathrm{~kW}$ (as pump) with water storage volume of $23.2 \mathrm{~m}^{3}$, and BAT=15.49 $\mathrm{kWh}$ 14 with life span of 1.9 years.

Table 2: Best cost result calculated by MGSA algorithm compared other techniques for case 1.

\begin{tabular}{ccccc}
\hline Algorithm & $\begin{array}{c}\text { Best } \\
\text { solution }\end{array}$ & Mean & $\begin{array}{c}\text { Worst } \\
\text { solution }\end{array}$ & $\begin{array}{c}\text { Standard } \\
\text { Deviation }\end{array}$ \\
\hline GA & 11941.09 & 11941.23 & 11941.37 & 0.07238 \\
PSO & 11941.93 & 11942.00 & 11942.09 & 0.03817 \\
GSA & 11940.88 & 11940.90 & 11940.93 & 0.01028 \\
MGSA & 11939.92 & 11939.93 & 11939.93 & 0.00334 \\
\hline
\end{tabular}


Table 3: Best cost result calculated by MGSA algorithm compared other techniques for case 2.

\begin{tabular}{ccccc}
\hline Algorithm & $\begin{array}{c}\text { Best } \\
\text { solution }\end{array}$ & Mean & $\begin{array}{c}\text { Worst } \\
\text { solution }\end{array}$ & $\begin{array}{c}\text { Standard } \\
\text { Deviation }\end{array}$ \\
\hline GA & 24131.73 & 24131.84 & 24131.98 & 0.06118 \\
PSO & 24132.07 & 24132.13 & 24132.21 & 0.03156 \\
GSA & 24130.71 & 24130.72 & 24130.74 & 0.00710 \\
MGSA & 24129.50 & 24129.51 & 24129.52 & 0.00335 \\
\hline
\end{tabular}

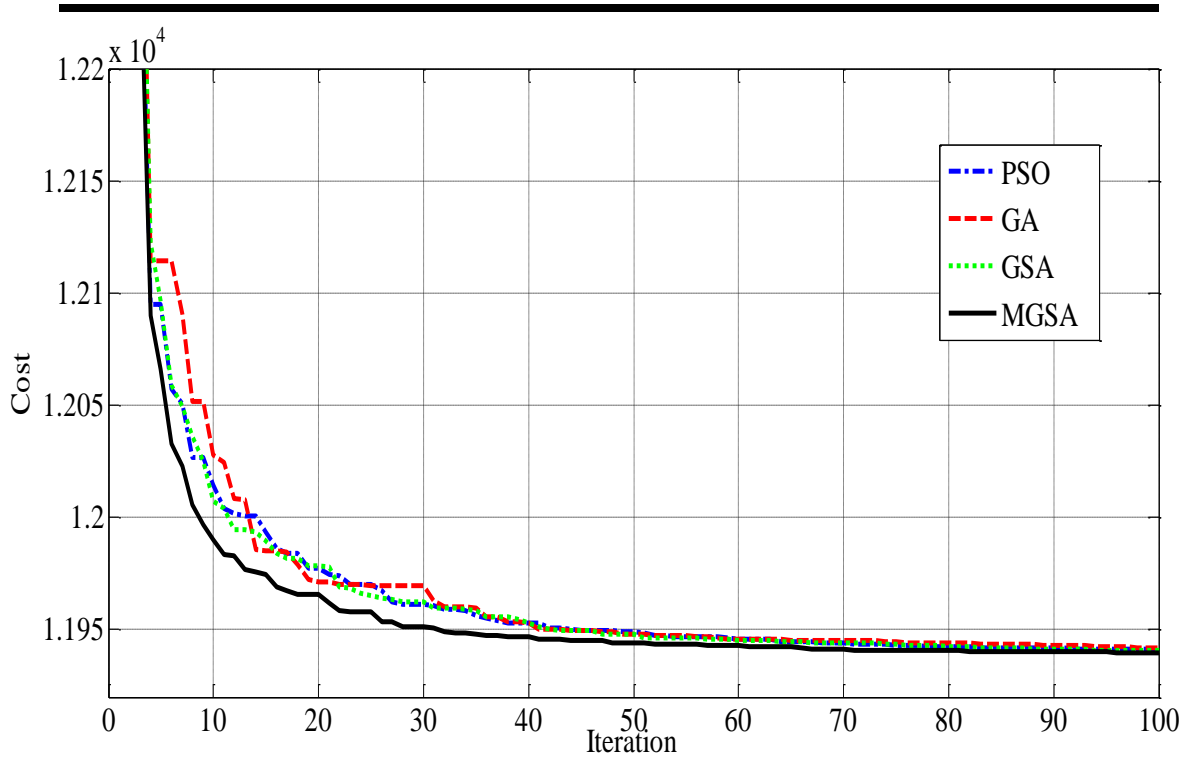

Figure 6. convergence of the algorithms for the problem with minimum cost for case 1 .

Fig. 7 indicates the hourly power trends of the system components including the 3

pump as turbine, the photovoltaic plant, the package of batteries and the diesel internal

combustion engine. Note that the negative values in the figure shows that the PAT 7 system is working as pump, and also for battery system it shows that the BAT is 8 charging. Fig. 8 and Fig 9 show the hourly trends of the BAT's SOC and the water 9 reservoir, respectively. It is very important to know that by using the proposed 10 management strategy, the batteries are keeping away from being charge and discharge many times at short intervals, which helps to increase their life span and hence reduce their cost. 


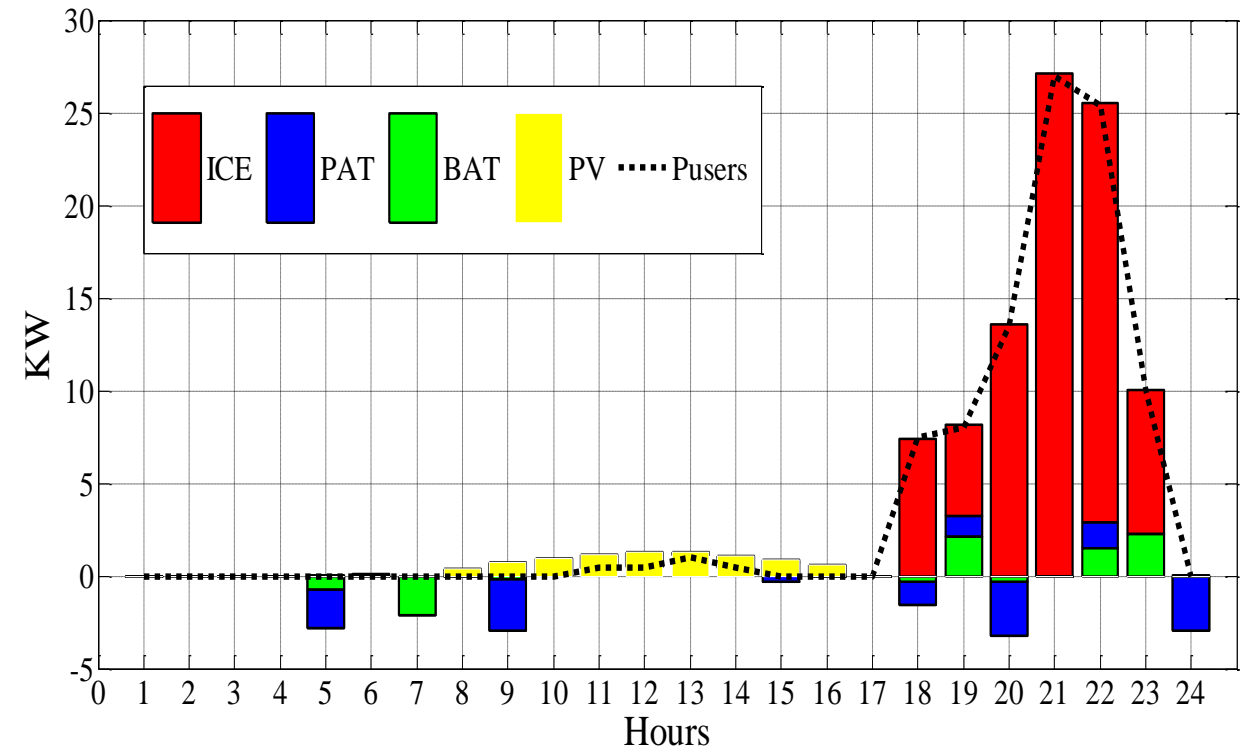

Figure 7. Hourly power trends of system components for case 1.

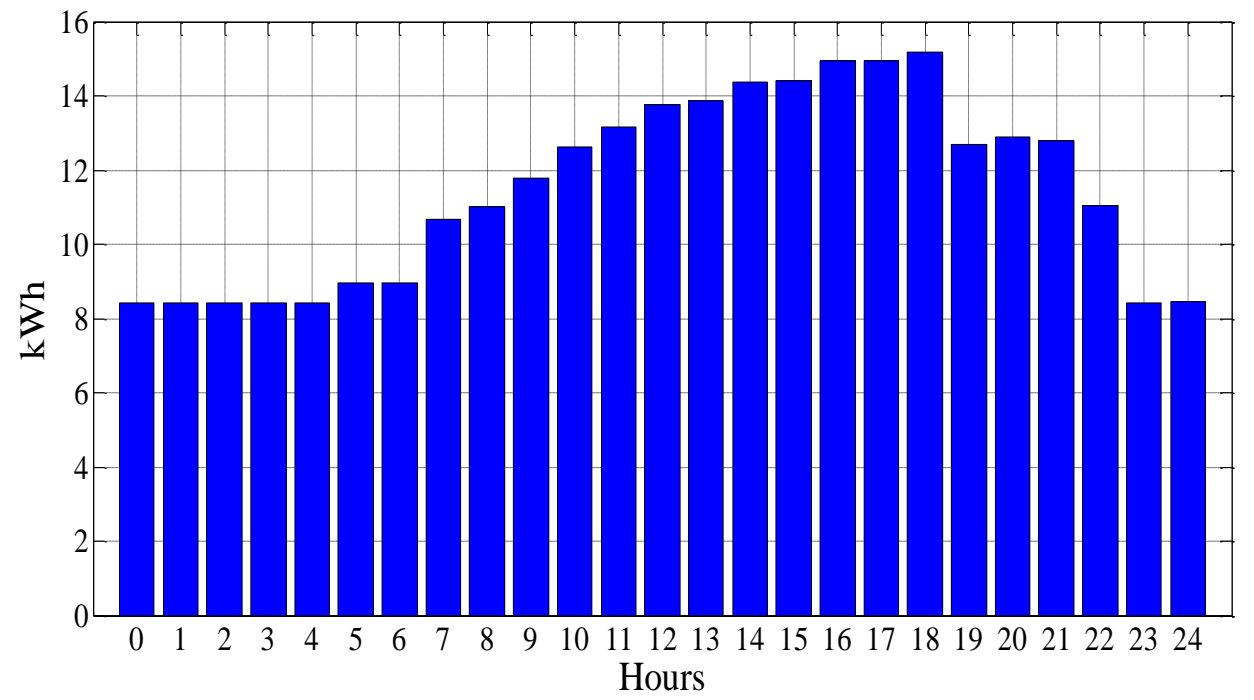

Figure 8. Hourly trends of the batteries SOC for case 1. 


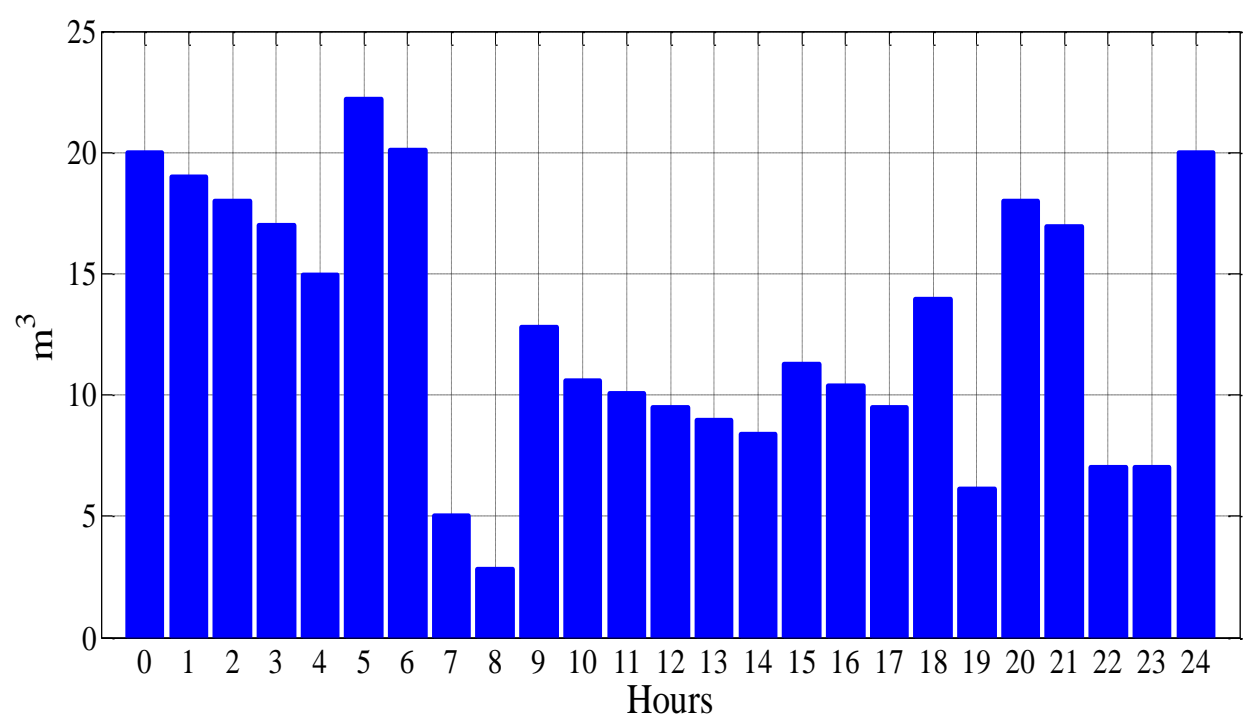

Figure 9. Hourly trends of the water tank for case 1.

Due to the low cost of the fuel, the PV and the BAT are not being operated to a great 4 extent. Also, the size of the PAT is associated with the required water. Despite anything 5 to the contrary, the use of the PAT and the battery allows fuel saving about $4 \%$ and $5 \%$ 6 of energy requirement, respectively. It is arousing the attention to notice that the 7 presence of PAT and the battery also makes certain of that the fossil fuel engine be able 8 to operate properly and supplies about $92 \%$ of electrical energy.

Table 3 shows the best cost result calculated by the proposed algorithm which is also compared to the results obtained by other algorithms used in the paper. According to the

Table 3, the minimum cost of $24129.51 €$ is calculated which are lower compared with other techniques. Fig. 10 also depicts the convergence of minimum cost of the 14 algorithms. 


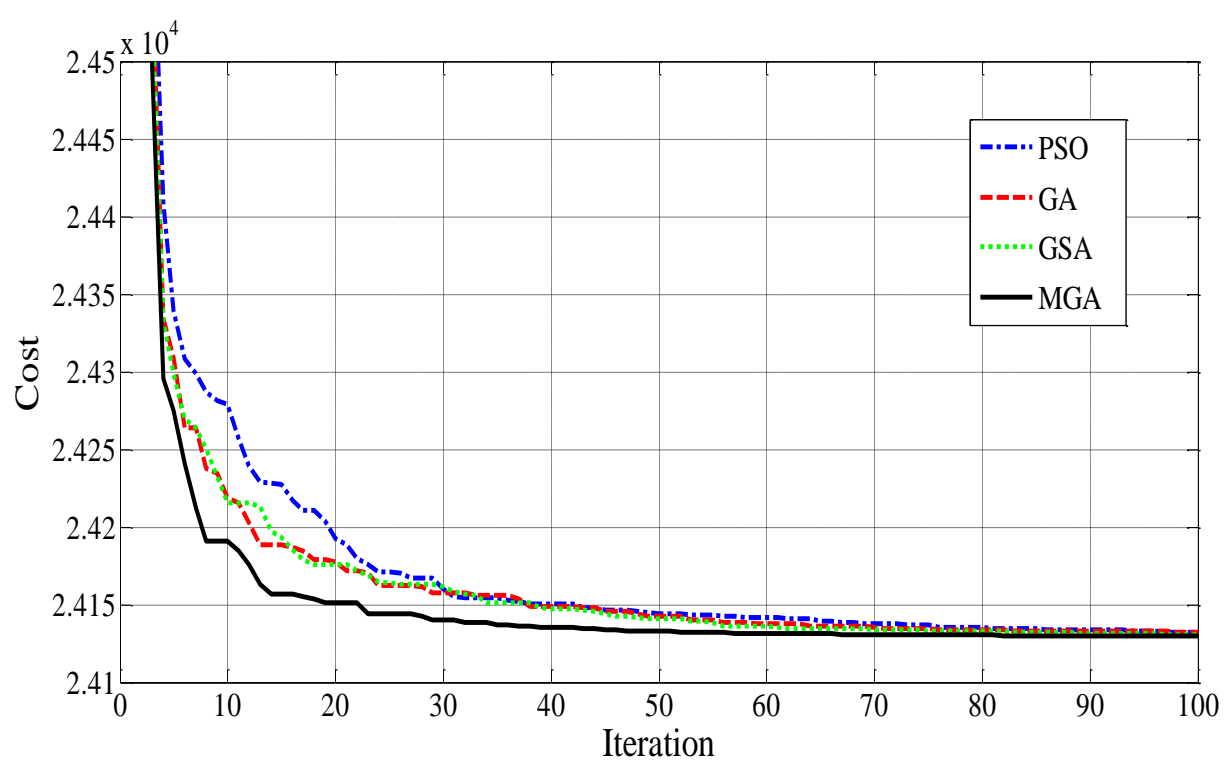

Figure 10. convergence of the algorithms for the problem with minimum cost 2 for case 2 .

By exploiting only renewable energy, the calculated optimum devices sizes are 5 $\mathrm{PV}=166 \mathrm{~m}^{2}, \mathrm{BAT}=131.7 \mathrm{kWh}$ with life span of 1.43 years, and PAT $=13.49 \mathrm{~kW}$ (as 6 pump) with water storage volume of $100 \mathrm{~m}^{3}$, which is the maximum determined water 7 stored volume in the optimization problem. Fig. 11 shows the daily power trends of system components including the PV, ICE, BAT and PAT. Fig. 12 and Fig. 13 show the hourly trends of the batteries SOC and the water tank, respectively. As it can be seen from these figures, the PV energy is accumulated and saved until needed as $11 \%$ of water, $79 \%$ of battery, and also $10 \%$ of it is used directly by consumers. It is also interesting to notice that the exploitation of the PAT system permits the battery not to get on top of the discharge maximum rate. 8 9 10 


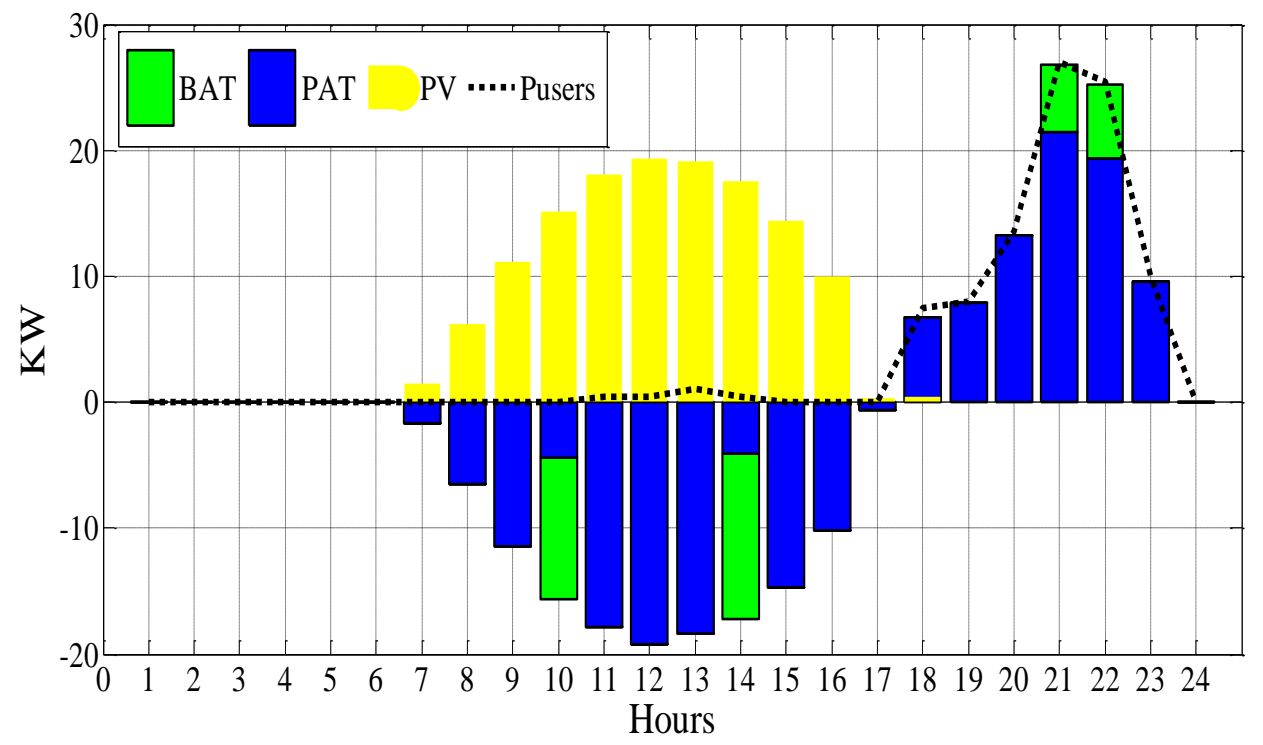

Figure 11. daily power trends of system components for case 2.

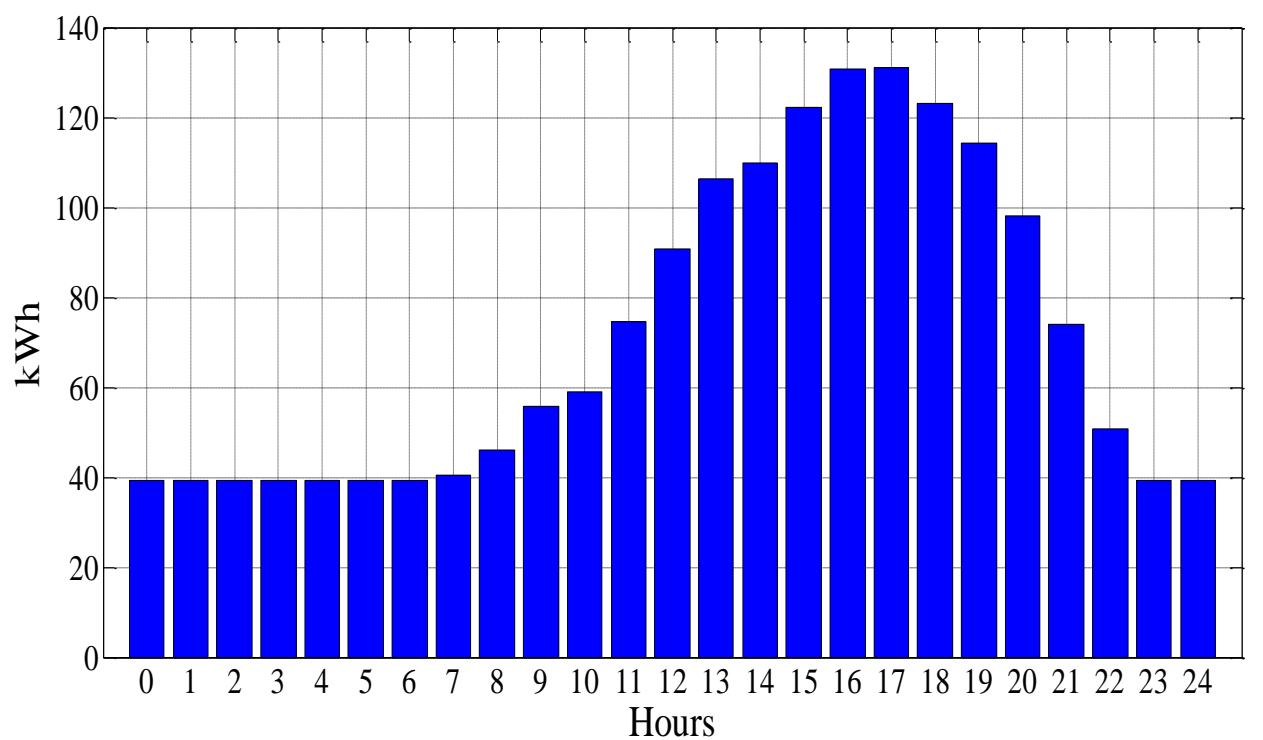

Figure 12. the hourly trends of the batteries SOC for case 2. 


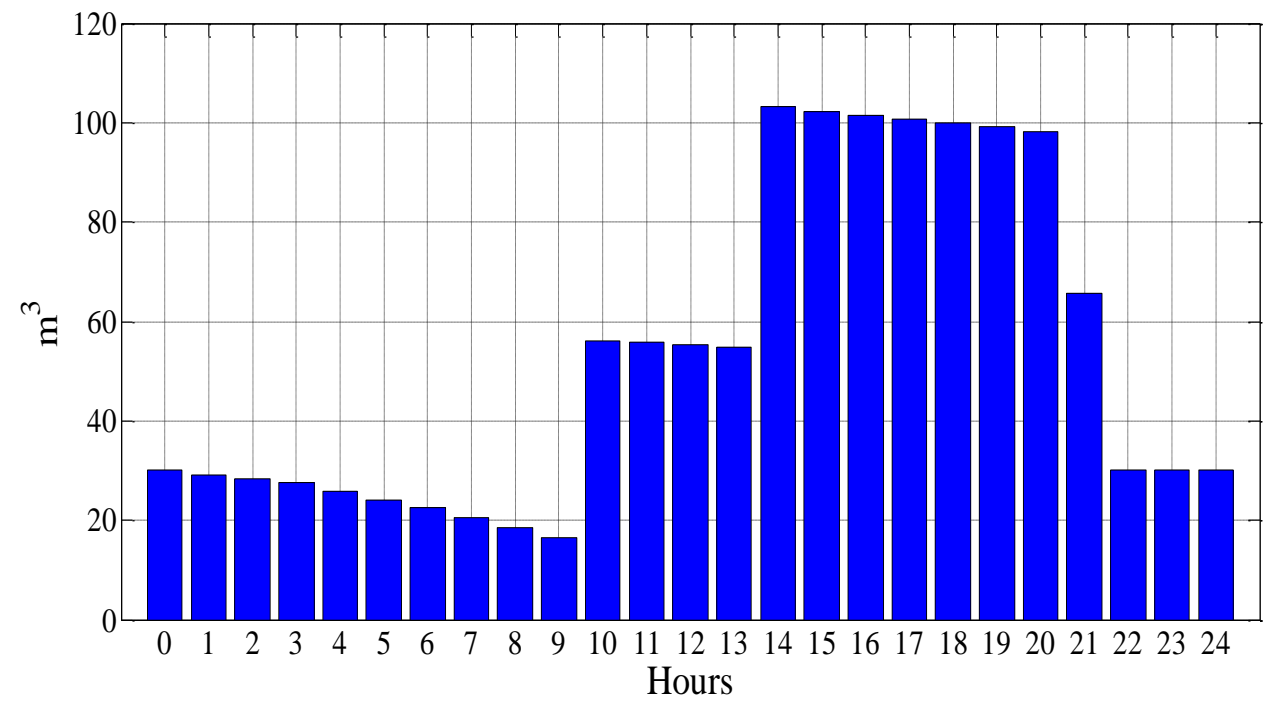

Figure 13. the hourly trends of the water tank for case 2.

\section{Conclusion}

In this paper, a modified GSA technique with an adapted mutation tactic is used to 6 find the best cost and management strategy of a PV-based PAT system that is composed 7 of a pack of batteries and a water reservoir for a remote area in Nigeria. By using the 8 proposed strategy, the cost of the system has been optimized in two cases by 9 considering both exploiting renewable energy sources along ICE and only exploiting 10 renewable energy sources. In the first case, the ICE system dominates all the other components due to the low cost of fuel, whereas in the second case, all renewable resources have been exploited and optimized in order to make a $100 \%$ renewable system with least possible cost. As reported acquired results have shown, the MGSA 14 has achieved an enhanced optimum result in comparison with other algorithms in finding the best cost and management strategy of the proposed hybrid system. 


\section{References}

[1] M. Cloutier and P. Rowley, "The feasibility of renewable energy sources for pumping clean water in sub-Saharan Africa: A case study for Central Nigeria," Renewable Energy, vol. 36, pp. 2220-2226, 2011.

[2] A. Ghoneim, "Design optimization of photovoltaic powered water pumping systems," Energy Conversion and Management, vol. 47, pp. 1449-1463, 2006.

[3] B. Bouzidi, M. Haddadi, and O. Belmokhtar, "Assessment of a photovoltaic pumping system in the areas of the Algerian Sahara," Renewable and sustainable energy reviews, vol. 13, pp. 879-886, 2009.

[4] A. Khelif, A. Talha, M. Belhamel, and A. Hadj Arab, "Feasibility study of hybrid Diesel-PV power plants in the southern of Algeria: Case study on AFRA power plant," International Journal of Electrical Power \& Energy Systems, vol. 43, pp. 546-553, 2012.

[5] S. Rehman and L. M. Al-Hadhrami, "Study of a solar PV-diesel-battery hybrid power system for a remotely located population near Rafha, Saudi Arabia," Energy, vol. 35, pp. 4986-4995, 2010.

[6] M. S. Ngan and C. W. Tan, "Assessment of economic viability for PV/wind/diesel hybrid energy system in southern Peninsular Malaysia," Renewable and Sustainable Energy Reviews, vol. 16, pp. 634-647, 2012.

7

8

9

[7] P. Lehman, C. Chamberlin, G. Pauletto, and M. Rocheleau, "Operating experience with a photovoltaic-hydrogen energy system," International Journal of Hydrogen Energy, vol. 22, pp. 465-470, 1997.

[8] A. González, E. McKeogh, and B. Gallachoir, "The role of hydrogen in high wind energy penetration electricity systems: The Irish case," Renewable Energy, vol. 29, pp. 471-489, 2004.

[9] M. Beccali, S. Brunone, P. Finocchiaro, and J. Galletto, "Method for size optimisation of large wind-hydrogen systems with high penetration on power grids," Applied Energy, vol. 102, pp. 534-544, 2013.

[10] G. Bekele and G. Tadesse, "Feasibility study of small Hydro/PV/Wind hybrid system for off-grid rural electrification in Ethiopia," Applied Energy, vol. 97, pp. 5-15, 2012.

[11] H. Sun, X. Luo, and J. Wang, "Feasibility study of a hybrid wind turbine systemIntegration with compressed air energy storage," Applied Energy, vol. 137, pp. 617$628,2015$.

[12] H. Ibrahim, R. Younes, T. Basbous, A. Ilinca, and M. Dimitrova, "Optimization of 39 diesel engine performances for a hybrid wind-diesel system with compressed air 40 energy storage," Energy, vol. 36, pp. 3079-3091, 2011.

[13] A. Bagdanavicius and N. Jenkins, "Exergy and exergoeconomic analysis of a Compressed Air Energy Storage combined with a district energy system," Energy Conversion and Management, vol. 77, pp. 432-440, 2014.

[14] H. Safaei and D. W. Keith, "Compressed air energy storage with waste heat export: An Alberta case study," Energy Conversion and Management, vol. 78, pp. 114-124, 2014. 
[15] Y.-T. Kim and Y.-H. Lee, "A hybrid energy storage system using pump compressed air and micro-hydro turbine," Renewable Energy, vol. 65, pp. 117-122, 2014.

[16] M. Kapsali, J. Anagnostopoulos, and J. Kaldellis, "Wind powered pumped-hydro storage systems for remote islands: a complete sensitivity analysis based on economic perspectives," Applied Energy, vol. 99, pp. 430-444, 2012.

[17] M. Beccali, M. Cellura, P. Finocchiaro, F. Guarino, S. Longo, and B. Nocke, "Life cycle performance assessment of small solar thermal cooling systems and conventional plants assisted with photovoltaics," Solar Energy, vol. 104, pp. 93-102, 2014.

[18] M. Beccali, M. Cellura, P. Finocchiaro, F. Guarino, S. Longo, and B. Nocke, "Life cycle assessment performance comparison of small solar thermal cooling systems with conventional plants assisted with photovoltaics," Energy Procedia, vol. 30, pp. 893903, 2012.

[19] M. Beccali, M. Cellura, F. Guarino, M. Mistretta, and S. Longo, "Eco-design of solar driven systems: a performance comparison between the Italian and the Brazilian context," Proceedings of 21st annual conference of the international group for lean construction, vol. 2 July, August, 2013.

[20] J. Margeta and Z. Glasnovic, "Theoretical settings of photovoltaic-hydro energy system for sustainable energy production," Solar energy, vol. 86, pp. 972-982, 2012.

[21] M. Amelio and S. Barbarelli, "A one-dimensional numerical model for calculating the efficiency of pumps as turbines for implementation in micro-hydro power plants," in ASME 7th Biennial Conference on Engineering Systems Design and Analysis, 2004, pp. 65-72.

[22] S. Joshi, A. Gordon, L. Holloway, and L. Chang, "Selecting a high specific speed pump for low head hydro-electric power generation," in Electrical and Computer Engineering, 2005. Canadian Conference on, 2005, pp. 603-606.

[23] A. Stoppato, G. Cavazzini, G. Ardizzon, and A. Rossetti, "A PSO (particle swarm optimization)-based model for the optimal management of a small PV (Photovoltaic)pump hydro energy storage in a rural dry area," Energy, vol. 76, pp. 168-174, 2014.

[24] G. Chicco and P. Mancarella, "Matrix modelling of small-scale trigeneration systems and application to operational optimization," Energy, vol. 34, pp. 261-273, 2009.

[25] G. Chicco and P. Mancarella, "Distributed multi-generation: a comprehensive view," Renewable and Sustainable Energy Reviews, vol. 13, pp. 535-551, 2009.

[26] A. Hamidat, B. Benyoucef, and T. Hartani, "Small-scale irrigation with photovoltaic water pumping system in Sahara regions," Renewable Energy, vol. 28, pp. 1081-1096, 2003.

[27] J. Kaldellis, E. Meidanis, and D. Zafirakis, "Experimental energy analysis of a standalone photovoltaic-based water pumping installation," Applied Energy, vol. 88, pp. 4556-4562, 2011.

[28] O. S. Ohunakin, M. S. Adaramola, O. M. Oyewola, and R. O. Fagbenle, "Solar energy applications and development in Nigeria: drivers and barriers," Renewable and Sustainable Energy Reviews, vol. 32, pp. 294-301, 2014.

[29] E. Rashedi, H. Nezamabadi-Pour, and S. Saryazdi, "GSA: a gravitational search algorithm," Information sciences, vol. 179, pp. 2232-2248, 2009.

[30] X. Han, L. Quan, and X. Xiong, "A modified gravitational search algorithm based on sequential quadratic programming and chaotic map for ELD optimization," Knowledge and Information Systems, vol. 42, pp. 689-708, 2015.

[31] P. K. Roy and C. Paul, "Quasi-oppositional gravitational search algorithm applied to short term hydrothermal scheduling problems," International Journal of Power and Energy Conversion, vol. 6, pp. 165-185, 2015.

[32] N. Gouthamkumar, V. Sharma, and R. Naresh, "Disruption based gravitational search algorithm for short term hydrothermal scheduling," Expert Systems with Applications, 2015 . 
[33] R. Resnick, D. Halliday, and J. Walker, Fundamentals of physics: John Wiley, 1988.

[34] M. R. Narimani, A. A. Vahed, R. Azizipanah-Abarghooee, and M. Javidsharifi, 2 "Enhanced gravitational search algorithm for multi-objective distribution feeder 3 reconfiguration considering reliability, loss and operational cost," IET Generation, 4 Transmission \& Distribution, vol. 8, pp. 55-69, 2014.

[35] Y. Wang, B. Li, T. Weise, J. Wang, B. Yuan, and Q. Tian, "Self-adaptive learning based particle swarm optimization," Information Sciences, vol. 181, pp. 4515-4538, 2011.

[36] G. Ventrone, G. Ardizzon, and G. Pavesi, "Direct and reverse flow conditions in radial flow hydraulic turbomachines," Proceedings of the Institution of Mechanical Engineers, Part A: Journal of Power and Energy, vol. 214, pp. 635-644, 2000.

[37] M. Shaaban and J. Petinrin, "Renewable energy potentials in Nigeria: Meeting rural energy needs," Renewable and Sustainable Energy Reviews, vol. 29, pp. 72-84, 2014. software.com/pvgis.php, accessed on 13 Sep 2015." 15

[39] "Climate, Average Weather of Nigeria. Available at: 16 http://www.nigeria.climatemps.com/, accessed on 13 Sep 2015." 17

[40] "Average Weather and Climate in Nigeria. Available at: http://www.weather-and- 18 climate.com/average-monthly-Rainfall-Temperature-Sunshine-in-Nigeria , accessed on 19 13 Sep 2015." 20

[41] S. Armstrong and W. Hurley, "A thermal model for photovoltaic panels under varying 21 atmospheric conditions," Applied Thermal Engineering, vol. 30, pp. 1488-1495, 2010.22 